\title{
Average Concentration from T1 to T2
}

National Cancer Institute

\section{Source}

National Cancer Institute. Average Concentration from T1 to T2. NCI Thesaurus. Code C132302.

The area under the curve over the interval from T1 to T2 divided by the leng th of the interval. 